Www.jmscr.igmpublication.org IGM Publication
Journal Of Medical Science And Clinical Research

An official Publication of IGM Publication

\title{
Survival Outcome of Infants in NICU - A Three Year Review
}

\author{
Authors
}

\section{Prof B I Sasireka $^{1}$, Dr D M Christe ${ }^{2}$, Prof S Baby Vasumathi ${ }^{3}$}

${ }^{1}$ MD DCH, Professor and Head, Department of Neonatology, Govt. Hospital For Women and Children Institute of Obstetrics and Gynecology, Madras Medical College

Email: b_i_sasireka@yahoo.com

${ }^{2}$ MBBS DGO PhD, Medical Research Officer, ICMR-HRRC NIRRH-FU, Institute of Obstetrics and

Gynecology, Madras Medical College

Email: cdmonte23@gmail.com,09789085577

${ }^{3}$ MD DGO, Professor And Head, Department of Obstetrics and Gynecology, Madras Medical College,

Director and Superintendent, Institute of Obstetrics and Gynecology, Madras Medical College

Address of Institution

Institute of Obstetrics and Gynecology,

No.11, Police Commissioner Hospital Road Egmore Chennai 600008

Corresponding Author

Dr D M Christe

MBBS DGO PhD, Medical Research Officer, ICMR-HRRC NIRRH-FU,

Institute of Obstetrics and Gynecology.

Email: cdmonte23@gmail.com,09789085577

\section{Abstract}

Aim: To retrospectively review survival rates and to assess the survival outcome of infants admitted in Newborn Intensive Care Unit [NICU].

Methods: The case records of all infants admitted in NICU, from 2012 to 2014 were scrutinized. Morbidity data detailing complications of admitted babies and medical complications of their mothers was noted. The birth weight, gestational age at birth of admitted babies, and the details of discharge from NICU were noted.

Results: Admission of neonates in the NICU, had risen from 31.4\% of live births in 2012 to current rates of $39.06 \%$ of live births in 2014. Major causes for admission were low birth weight and prematurity, followed by jaundice and birth asphyxia. The overall survival rate was $89.6 \%$ in 2012, and risen to $91.6 \%$ in 2013 and $91.7 \%$ in 2014.

Conclusion: Among extreme premature group of babies [GA (gestational age) < twenty eight weeks] there was a steady increase in survival rates yearly and in 2014, $14 \%$ of babies survived. There was no change in survival rates of moderate preterm group [GA 32 to 33 weeks] and in the late preterm group [GA 34 to 37 weeks ], there was an increase in survival rates by $4 \%$. Term babies of GA 37 to 42 weeks had survival rates of $95 \%$ in 2013 and $96 \%$ in 2014.

Keywords : survival neonates, Newborn intensive care, NICU, preterm, small for date 


\section{Aim}

To retrospectively review and assess the survival outcome of infants admitted in Newborn Intensive Care Unit $[\mathrm{NICU}]^{1,2,3}$.

\section{Methods}

The case records of all infants admitted to NICU, from 2012 to 2014 were scrutinized. The admitted numbers, along with the total number of live births yearly were noted. To assess the survival outcome of the admitted babies, Morbidity data detailing complications of admitted babies and medical complications of mothers of admitted babies ${ }^{4,5,6,7}$, birth weight, gestational age at birth, and the details of discharge from NICU were also noted $^{7,8,9,10}$.

\section{Results}

The year 2012 saw a total number of admissions of 4329 infants, and 4831 in 2013 and 5000 in 2014, with a yearly increase of 200 to 500 admissions. The overall survival rates were higher than $89 \%$, in all the three years and the last two years saw overall rates of survival of $91.6 \%$ and $91.7 \%$. [fig. 1$]$

\section{Major Causes of Admission in NICU}

The Morbidity data detailing complications of admitted babies was assessed. [fig.2] The major cause for admission was low birth weight [LBW] in all the three years ${ }^{8,9,10}$. It was the cause, in $34.6 \%$ of the total admissions, in 2012 and in 2013 and showed a minimal decrease by a little less than $3 \%$ in $2014^{9,10,11}$. Prematurity was the major cause in $25 \%$ of admissions. Jaundice was the cause of admissions in $9 \%$ of babies in 2012 and rose to $14.3 \%$ of babies in $2014^{12}$. Birth asphyxia was causative factor for nearly $6 \%$ of admissions in all three years.

Sepsis was the reason for admission in $5 \%$ of total in 2012 and was reduced to nearly $4 \%$ in $2014^{13}$. Hyaline Membrane Disease was responsible for admission in $4 \%$ of the total ${ }^{14,15}$ numbers of babies admitted and followed by congenital malformations in around $3 \%$ of total admissions ${ }^{16,17}$. Other reasons which necessitated admissions for newborns were Intra Uterine Growth Retardation, anemia of newborn, Infant of Diabetic Mother, ${ }^{4}$ [in14.5\%], and Transient Tachypnea of Newborn.

\section{Survival of Babies By Gestational Age- Year Wise}

The survival rate of extreme preterm group [GA < 28 weeks] was $8.06 \%$ in $2012^{17,18}$. In the very premature group [GA 28 to 31 weeks], more babies were only GA 28 weeks, and there was a yearly decrease in survival rates. Survival of moderate preterm babies [GA 32 to 33 weeks] was $83.1 \%$ in 2012 and was slightly lowered to 82.2 $\%$ in 2014. Late preterm group [GA 34 to36 weeks] had good survival rates of $89.74 \%$ in 2012, which had increased to $93.37 \%$ in 2014. Term babies [GA 37 to 42 weeks] had survival rates of $95.27 \%$ in 2012 and $96.36 \%$ in 2014 . [fig.3] The survival of post term babies [GA $>42$ weeks] was $100 \%$ in 2012. In 2013 there was a steep tenfold rise in admissions of post term babies and $87 \%$ of babies survived. ${ }^{19,21}$ In 2014 ,the overall survival of babies admitted in NICU was $91.7 \%{ }^{1}$. At least $13 \%$ of Extreme preterm babies and $49 \%$ of very premature babies survived. The survival of moderate preterm babies was $82 \%$ and $93 \%$ of late preterm babies survived. The survival rate was $96 \%$ for term babies, and 80 $\%$ for post term babies.

\section{Conclusion}

Survival outcome of infants had increased steadily over the last three years. ${ }^{22}$ The overall survival rates of infants admitted in NICU, at Govt. Hospital for Women and Children was $89.6 \%$ in 2012 and rose to a rate of $91.6 \%$ in 2013 and to $91.7 \%$ in $2014^{9,22}$. The extreme premature group born before 28 weeks, with very low birth weight of one $\mathrm{kg}$ and below, had a survival of 13\% [fig.4] and around $48 \%$ of very premature babies survived. All three years saw survival of least $82 \%$ of moderately preterm babies. Late preterm babies had high survival rates of $90 \%$ in 2012 and $93 \%$ in 2014. Term babies had survival rates of $95 \%$ in 2013 and $96 \%$ in 2014. 
Fig. 1 Year wise Admission - Survival of Babies In NICU

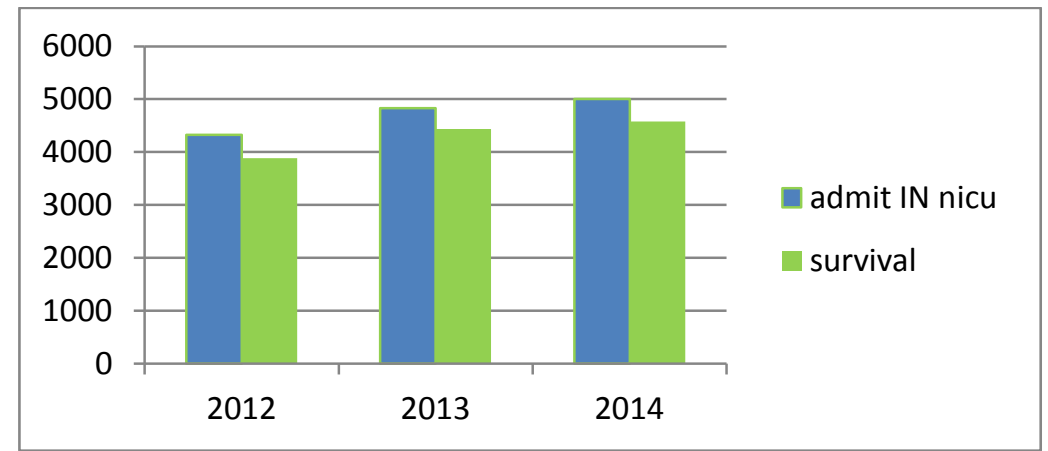

In all the three years the overall survival rates were higher than $89 \%$

The last two years saw overall percentage of survival of $91.6 \%$ and $91.7 \%$

Fig. 2 Major Causes of Admission of Babies In NICU

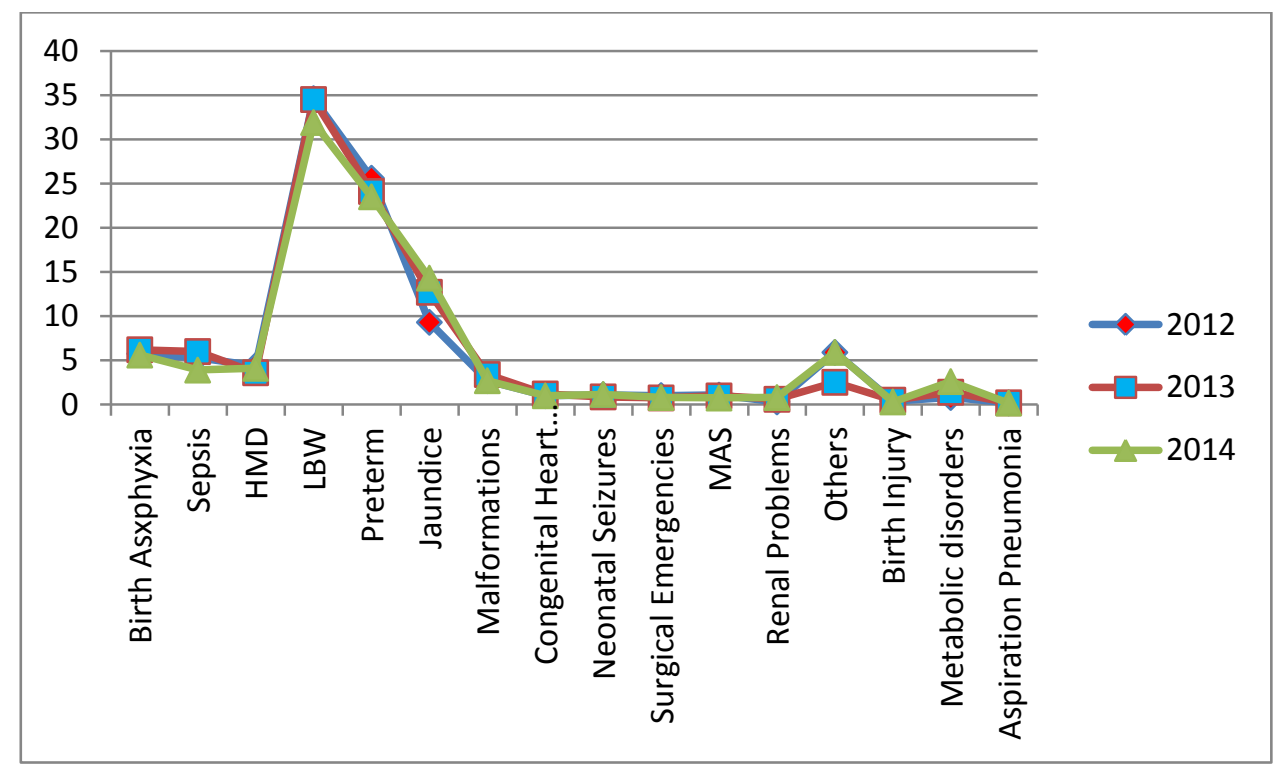

In the years from 2012 to 2014, low birth weight and prematurity, followed by jaundice and birth asphyxia were the main reasons necessitating admission in NICU.

A large number of babies in the Low Birth Weight Group of 1.5 to $2.5 \mathrm{Kg}$ required admission.

Numbers of babies shown as percentage of total admissions.

Fig . 3 Yearly Survival of Babies By Gestational Age

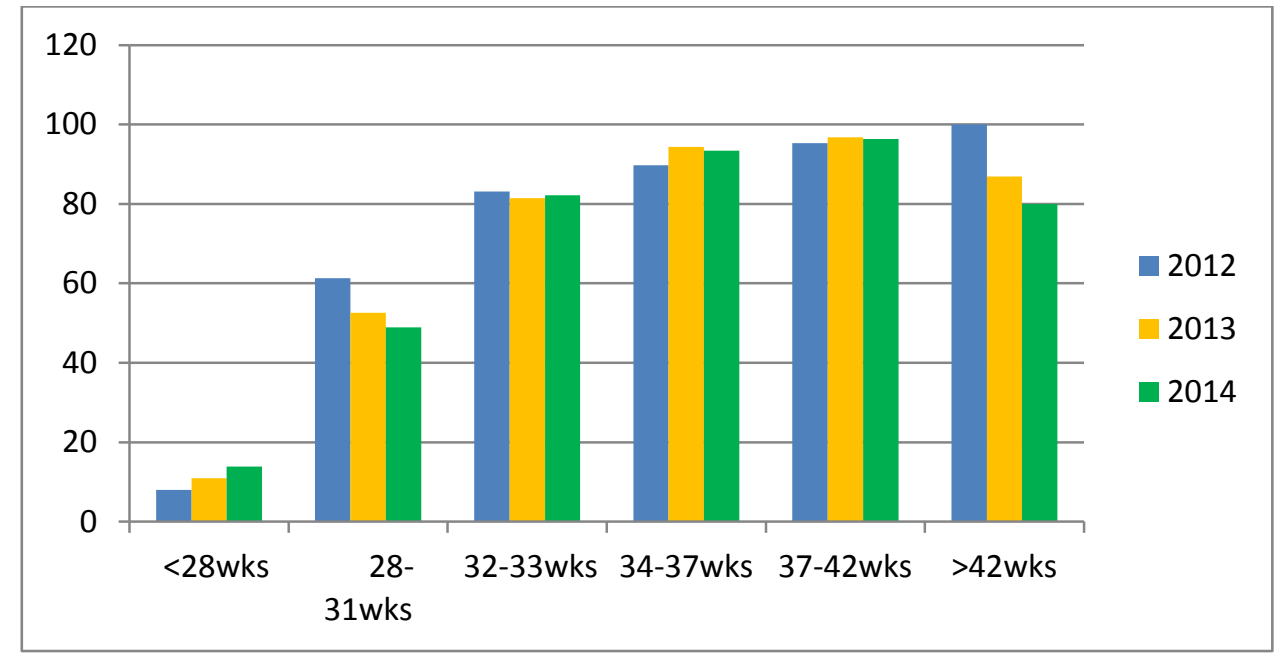


The survival rate of extreme preterm group [GA $<28$ weeks] was $8.06 \%$ in 2012.Survival of moderate preterm babies [GA 32 to33 weeks] was $83.1 \%$ in 2012 and was slightly lowered to 82.2 $\%$ in 2014. Late preterm group [GA 34 to36 weeks] had good survival rates of $89.74 \%$ in 2012 which had increased to $93.37 \%$ in 2014. Term babies [GA 37 to 42 weeks] had survival rates of $95.27 \%$ in 2012 and $96.36 \%$ in 2014

Fig. 4 Survival of Babies By Birth weight Year wise

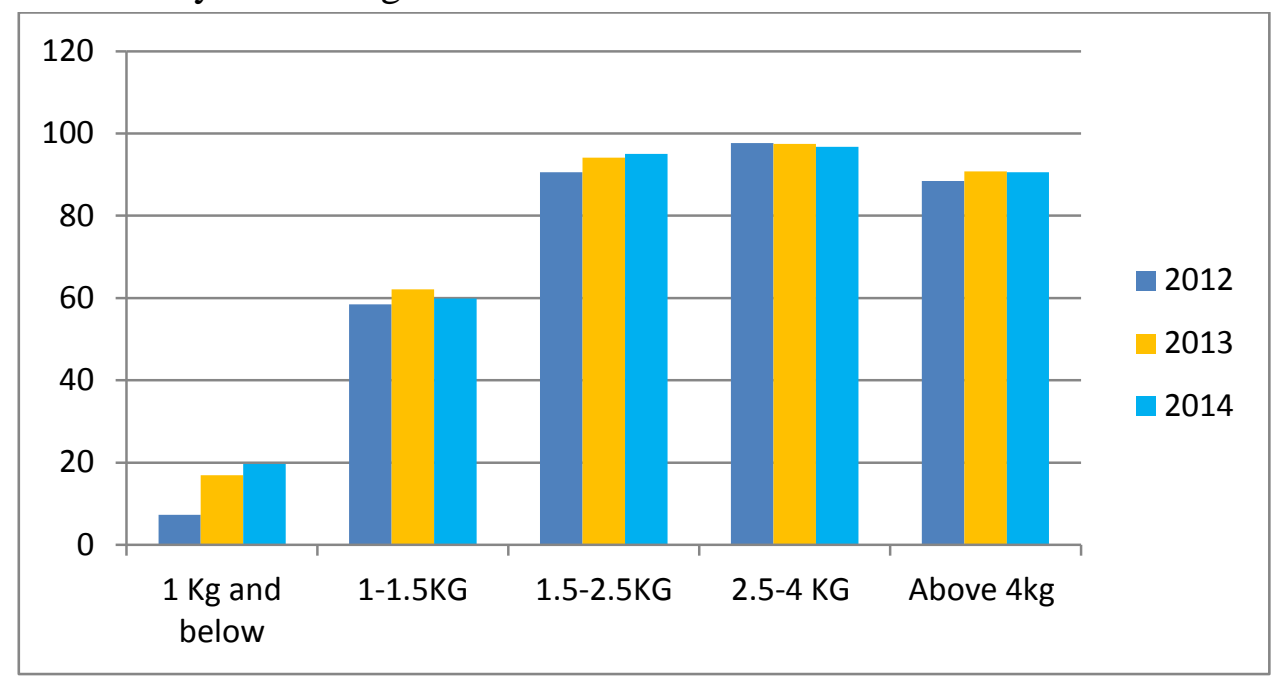

The survival of babies by birth weight is shown above.

Among extreme premature group of babies of birth weight below one $\mathrm{Kg}$, there was a steady increase in survival rates yearly from $7 \%$ in 2012 to a better figure in 2014 where $20 \%$ of babies survived.

Among the very premature group of birth weight of $1 \mathrm{Kg}$ to $1.5 \mathrm{Kg}$ the 2012 saw the survival of $59 \%$ of babies, and continued at 60\% survival of babies in this birth weight group in 2014.

There was a marginal increase from the already good figures of $91 \%$ survival in 2012 to $95 \%$ in 2014 for the birth weight group of $1.5 \mathrm{Kg}$ to $2.5 \mathrm{Kg}$.yearly decrease and in $201449 \%$ of admitted babies survived.

There was no significant change in survival rates of babies in the birth weight group of $2.5 \mathrm{Kg}$ and was $97 \%$ in 2014. Term babies of birth weight above $4 \mathrm{Kg}$, the survival rates were $88 \%$ in 2012 and rose to $91 \%$ in 2014.

\section{Acknowledgement}

The authors acknowledge with thanks the Director of IOG, for granting permission to present the data in this article. The authors thank all the staff of NICU and ICMR who helped, in preparation of this article.

\section{Conflict of Interest Statement}

The authors have no conflicts of interest relevant to this article

\section{References}

1. Chirag D. shah, Swati Upadhyay, Narrendra N.S, K.M .Mehariya. Study of
Perinatal outcome of Tertiary Care Hospital, Journal of Neonatology,2013, Vol-27, No: 1, Pg:14-16,18,19.

2. Malhotra S, Zodpey SP, Vidyasagaran AL, Sharma K, Raj SS, Neogi SB, Pathak G, Saraf AJ, Assessment of essential newborn care services in secondary-level facilities from two districts of India. 2014 ,Vol-32,No:1, Pg:130 - 41.

3. S.Sengupta,V.Carrion, J. Shelton,R.J. Wyn n, R.M. Ryan, K. Singhal, S. Lakshminrusimha, JAMA .Adverse Neonatal Outcomes Associated With Early-Term 
Birth. 2013,Vol-167,No:11,Pg:1053-1059, doi:10.1001.

4. Potti S, Jain N J ,Mastrogiannis DS, Dandolu V. Obstetric outcomes in pregnant women with diabetes versus hypertensive disorders versus both. J Matern Fetal Neonatal Med,2012.Vol- 25, No:4, Pg: 358-8, doi:10.3109/14767058.2011.580403

5. S Srivastava, A Gupta, A Bhatnagar, S Dutta. Effect of Very Early Skin to Skin Contact on Success at Breastfeeding and Preventing Early Hypothermia in Neonates. Indian Journal of Public Health.2014. Vol- 58,No: 1,Pg: 22-2

6. Author manuscript.Lancet.2014; Vol- 384, No:9947, Pg: 957-979. doi: 10.1016/S0140 - 6736 (14) 60497- 9.

7. K Mukhopadhyay, D Louis, R Mahajan, Andp Kumar. Predictors of Mortality and Major Morbidities in Extremely Low Birth Weight Neonates. Indian Pediatrics . 2013.Vol-50,No-1, Pg : 1119 to 1123.

8. UNICEF FACT SHEET - National Institute of Medical Statistics -Indian Council of Medical Research. Infant and child mortality in India. Global, regional, and national levels of neonatal, infant, and under -5 mortality during 1990-2013: A systematic analysis for the Global Burden of Disease Study

9. WHO

PRETERM BIRTH-

FACT SHEET www.who.int/mediacentre/factsheets/fs363/en

10. ACOG COMMITTEE OPINION NO. 560 April 2013 The society for Maternal -Fetal Medicine. Medically indicated late preterm and early term deliveries.

11. S Chattopadhyay, A Das, and S Pahari.Fetomaternal Outcome in Severe Preeclamptic Women Undergoing Emergency Cesarean Section under Either General Or Spinal Anesthesia. J Pregnancy. 2014: 325098, doi: $10.1155 / 2014 / 325098$.
12. K KSukla, $\mathrm{P} \quad \mathrm{K} \quad$ Tiwari, Ashok Kumar, and R Raman. Low Birth weight ( LBW ) and Neonatal Hyperbilirubinemia ( NNH ) in an Indian Cohort: Association of Homocysteine, Its Metabolic Pathway Genes and Micronutrients as Risk Factors. 2013.Vol -8 No:8, Pg: e71587. doi: 10.1371/journal. pone. 0071587.

13. Iwamoto A, Seward N, Prost A, Ellis M, Copas A, Fottrell E, Azad K, Tripathy $P$, et al. Maternal infection and risk of intrapartum death: A population based observational study in South Asia.BMC Pregnancy Childbirth. 2013. Dec 28;13:245. doi: 10.1186/1471-2393-13245.

14. V Mahajan, Amarpreet Kaur, A Sharma, C Azad And V Guglani. Modifiable Factors for Prevention of Childhood Mortality. Indian Pediatrics .2014.Vol51,No:1,Pg:45-47.

15. P V. Mally, KD.Hendricks-Munoz, S Bailey. Incidence and Etiology of late preterm Admissions to the Neonatal Intensive Care Unit and its Associated Respiratory Morbidities when compared to Term Infants.Amer $\mathbf{J}$ Perinatology. 2013, Vol-30, No: 5 , Pg:425 - 432, doi: 10.1055/s-0032-1326989

16. International Neonatal Network, Scottish ,Neonatal consultants, Nurses collaborative study group. Risk adjusted and population based studies of the outcome for high risk infants in Scotland and Australia. Arch Dis Child Fetal Neonatal Ed, 2000 ,Vol- 82 , No: 2,Pg:118 -23 .

17. Ehernthal DB, Hoffman MK, Jiang X, OstrumG. Neonatal outcomes after implementation of guidelines Limiting elective delivery before 39 weeks of gestation .Obstet Gynecol, 2011. Vol -118,No:5.1047-55, doi: 10.1097/AOG.0b013e3182319c58 
18. S S Roy, R Mahapatra, 'S Rath, A Bajpai, VSingh, SRath, NNair, PTripathy, R Kumar Gope, R Sinha, A Costello, CPagel, and A Prost, Improved neonatal survival after participatory learning and action with women's groups: a prospective study in rural eastern India. Bull World Health Organ, 2013, Vol -91,No:6. Pg:426-433B, doi: 10.2471/BLT.12.105171.

19. Madan L, Puri L, Jain N J, Grotegut C, Nelson D, Dandolu V. Characteristics of obstetric Intensive care unit admissions in New Jersey. J Matern Fetal Neonatal Med, 2009. Vol- 22 , No: 9. Pg: 785-90, doi: 10.3109/14767050902874097

20. R. Narayan. A study of the pattern of admissions and outcome in a neonatal intensive care unit at high altitude Sri Lanka Journal of Child Health. 2012 ,Vol -41, No:2, Pg:79- 81.

21. N Garg, B Singh, D Kumar, S K Mittal, S Kumari. Morbidity and Mortality in low birth weight babies in self - financing level III Neonatal intensive care unit. Journal of neonatology. 2013. Vol-27, No: 4. Pg: $: 10-1$

22. B I Sasireka,D M Christe, R Senthil Prabu , S Baby Vasumathi. Recent Advances in NICU in A Referral Centre. Journal Of Paed.,Obstetrics \& Gynaecology .2015.Vol.6. No.4: Pg 11-17. 